\title{
The Influence from College Physical Education on the Development of Students' Physical and Mental Health
}

\author{
Xin-ying LIU * \\ The School of Physical Education, Wuhan Business \\ University, Wuhan, Hubei, China \\ 15239059@qq.com
}

\author{
Zhong Wu \\ The School of Physical Education, Wuhan Business line \\ University, Wuhan, Hubei, China \\ 7849800@qq.com
}

\begin{abstract}
Promoting and gradually perfecting the development of students' physical and mental health in school physical education is an important aspect of improving the quality of physical education. Physically and psychologically comprehensive development of students is an important factor in social progress. Because of unique te aching methods and teaching laws, physical education can provide superior conditions and environments for the continuous all-round development of students in physical education. By studying the impact of physical education on development of students' physical and mental health, favorable conditions can be provided to support cultivating good pers onalities of students.
\end{abstract}

Keywords-college physical education; physically and psychologically healthy development; influence

\section{INTRODUCTION}

It is an era that modern education should pay more attention to the quality training. In the education process, colleges and universities are no longer just pursuing better grades, but putting forward higher requirements of students. In modern education, students need to be trained in all dimensions so as to require students to be qualified with comprehensive qualities and abilities in their future lives and work. Among the overall education, physical education is rated as the most basic course to urge the students to go in for physical training colleges and universities education, and acts as an important part of education. Physical education can effectively promote students to adapt to and integrate into society, and can promote students to fully develop themselves physically and psychologically in the process of participating in physical education. The full attention should be paid to the comprehensive development of students' physical and mental health in physical education. The education should be under way and be optimized through teaching experiments so that the quality of physical education can be fundamentally improved.

\section{ACtions of Physical EdUCATION on DeVElopment of Students' Physical and Mental HEalth}

\section{A. Cultivate teamwork spirit of students and improve interpersonal skills of students}

Every student has the desire to learn and develop themselves. Therefore, both the true freedom and learning space must be given back to students so that students can be provided with sufficient conditions for independent exploration[1]. After entering into colleges and universities, students are considerably looking forward to the group life. And sports activities can create a platform for mutual smooth, free and equal communication. Firstly, sports activities are conducted in public places, providing a desirable external condition for contacts between students. Secondly, sports activities are usually carried out in the form of team activities such as football, basketball and other group projects. It will help students organize a natural small group, provide a platform for communication and enable students to quickly find and talk on some topics. Thirdly, there are explicit and fixed regulations on sports programs. As a result, there will be no unreasonable controversy when students are performing sports activities under such conditions. Moreover, participating in sports activities in a harmonious atmosphere is able to cultivate healthily developed mind and body and an outgoing personality.

\section{B. Build the strong will of students}

Mastering both professional technical knowledge and material life is a basic requirement of students. If such a requirement is satisfied, students will pursue spiritual needs. Sports can help students meet their spiritual needs of mental regulation and individual development[2]. In the process of participating in physical activities, there will be different degrees of competitions among students more or less. In order to win in the competition, the self-esteem of students will be triggered in order to win. And furthermore, such an initiative that will not disappear unreasonably will promote students to develop a spirit of unyielding and non-giving up. The furious competition will also make students feel sort of unpleasant in intensely competitive physical activities. Such feelings are similar to the encountered by students in their daily learning and lives, and after a long time, students will develop a strong will.

\section{Make contributions to students' developing a healthy body}

Physical education must adhere to taking the "health comes first” as the guiding idea, pay attention to individual differences and different needs of students, and correctly induce and develop their personalities[3]. 
In modern times, there is heavy pressure of life on the public. Such pressure is from various aspects, and the increase in the load of study and work will multiply the pressure and lead to exhaustion. Therefore, physical health and sufficient strength are expressively important for people's daily life. Students spend most of their time studying hard at school and rarely have time and opportunities of exercise. Even if they have time, the students are often subject to school pressure and it is difficult to perform real exercise. However, if they alternate work with rest and choose a long-term exercise program that they are interested in or are good at, the students will benefit from exercising significantly. Under such circumstances, students can develop a lifelong awareness of sports. Even if they subsequently leave school and enter into society, this awareness of constantly exercising can also facilitate students' perseverance in physical exercise, which is also very important for the cultivation of high-quality talents in China.

\section{Cultivate and improve the overall competence of students}

Participating in physical activities can examine the students' abilities and qualities in various aspects, including capacities of self-learning, interpersonal communication skills, and cooperative abilities. As a powerful socialization method, physical activities play a positive role in promoting to cultivate sense of competition of high school students[4]. The physical education equipped with multiple functions can contribute to the development of overall competence of student.

\section{Problems in Physical Education Teaching}

\section{A. Lack of sports programs}

At present, there is deficiency in most sports teaching programs of schools. Some sports programs do not have a teaching plan. This is not conducive to self-exploration of students so that they may fail to explore their own potential. That is to say, students cannot choose proper sports programs which the students are good at according to their interests, which poses restrictions on the development of personalities when students are participating in sports events.

\section{B. Teachers play a dominant role}

In the traditional physical education teaching process, it is often the teaching mode that the teacher is speaking and the students are listening, and the model has the aim that the teacher works well in terms of speaking and the students behave well in listening and learning. Such a kind of teaching model puts the teacher in the main position, leading to the poor effect. It usually appears that students cannot find the interest and pleasure of learning, and even will be tired of listening. So now in the process of physical education teaching, teachers should learn to put themselves in the students' position, fully understand the students' ideas, prepare for the change of roles, and consider the students as the main body in physical education to develop the students' personalities. Teachers should also encourage students to think independently, innovate, and to explore unknown areas to enrich themselves, and the teachers should further allow students to achieve independent thinking, constant improvement and opening of individuality in a free and harmonious learning atmosphere.

\section{Non-layered teaching and overgeneralization}

In the traditional physical teaching process, the main consideration is the student's ability to accept knowledge and teachers tend to implement unified teaching. However, with the progress of society, the methods and ways of education should be changed. Through the ordinary contact with each student, the teacher should fully understand the students' advantages, interests and hobbies, logical thinking and others. And then, according to the different characteristics of each student, the teachers can adopt appropriate teaching modes and methods. And furthermore, in the process of teaching activities, students should be guided to find problems in the process of learning and to solve problems through their independent exploration, which can improve the will and qualities of students.

\section{Ignorance of individual variation and failure in teaching according to the students' natural abilities generally}

Each student is an independent individual, with different interests, different acceptance capabilities, and different physical conditions. Teachers should carefully understand and correctly view these differences, and determine different and targeted teaching strategies and methods for each individual based on these differences. In traditional physical education teaching, teachers tend to set up teaching plans and courses in advance, and then implemented unified teaching. The actual implementation of this teaching model fails to take effect as expected, which limits the thinking distribution of students in the process of participation so that students can't give full play to their own Advantages, or display their talents. Consequently, the development of student personality is limited.

\section{E. Insufficiently deep and incoherent teaching}

At present, the teaching is insufficiently deep in terms of some sports programs. Students usually come into slight contact with a sports program and do not have a comprehensive understanding the project, or any grasp of sports skills upon the ending of the sports program. Learning. There is no follow-up teaching plan, which leads to lack of coherence in the process of learning. It is difficult to achieve the goal of promoting the development of student personality in physical education.

\section{F. Short of scientific and systematic teaching}

Teaching is a systematic project. In order to do a good job in physical education, joint efforts should be made by teaching staff and students. At present, the curriculum is not combined with the actual needs of students and the real conditions of students as to each sports program. There is not enough attention paid to the actual teaching effect of the curriculum.

\section{Strategies for the All-Round Development of Students' Physical and Mental Health}

\section{A. Putting the development of students first}

Physical education teaching is the most important task of quality education. Training creative talents required by society 
is the goal of education. In the routine management of the school, we must pay much attention to both the overall harmonious development and the students' individual differences for the sake of sustainable development of school's teaching cause. It is necessary to formulate a scientific teaching management system and build a fair and reasonable competitive environment based on the joint participation of teachers and students. It should be ensured that teachers and students can make academic researches, transmit knowledge, explore truth, and create culture in a free, coordinated and relaxing environment, and give full play to the enthusiasm and creativity of teachers and students[5]. Student's creativity is not generated under the outside pressure, but is motivated by the joy and challenges of the leaning itself. The perfect integration of school' interests with personal interests are the common goal of schools, teachers and students. It is essential for the participant parties to work together to focus on each student's unique and colorful personalities, create a harmonious environment for students' growth, and to optimize the physical education model so that every student can freely choose the sports items they are interested in and fully develop their personalities.

\section{B. Provide excellent physical educational environment}

Physical education is an important part of school education. Under the overall environment of quality education, students' individuality is promoted. Physical education can provide students with unique and irreplaceable environmental advantages due to its unique openness and compatibility.

During physical education activities, teachers should consider the actual situations, innovate the teaching mode as well as teaching tools, and carry out different forms of teaching activities based on the original hardware and teaching aids so as to assist students in exhibiting their individuality. Thus, physical education teachers are required to break the traditional model, boldly carry out teaching reforms, update teaching methods, and to integrate modern learning concepts into teaching activities. Furthermore, it is necessary to combine physical education with modern information with the integration of entertainment, openness, fitness with other aspects, actively and boldly accept new theories, concepts, and methods reported by students, find teaching modes and methods suitable for students, and to create more relaxing and pleasant learning atmosphere so that students' personalities can be fully demonstrated.

\section{Reinforce the cultivation of students' practical ability}

As regards physical education teaching, dominant role of students should be explicitly defined and be given full play. In case of problems in the process of exploration, students should actively pose questions, make appropriate assumptions, and work hard to solve problems. The students should personally participate in and actively explore every question, discover the key points of the problem by the knowledge that they have grasped, fully expand the thinking, carry forward the spirit of exploration without giving up, work hard to find out the answer, and promote this kind of spirit to life and develop good habits.

\section{Strengthen the cultivation of students' independent learning ability}

In the traditional physical education teaching, the main teaching method is that the teacher carefully explains to the students while the students listen and learn seriously, and then the teacher informs the students of the difficult points and asks the students to practice and review repeatedly for grasp the knowledge. However, in the process of implementation, students often feel bored because this single type of learning mode. Once they encounter problems that they cannot solve, they will be afraid to face the challenges and even eager to give up, and gradually lose interest in learning.

Consequently, in the physical education process, students groups should be actively encouraged to learn. In addition, it is required to give students free and relaxing learning space, and to allow students to freely express and exchange opinions in discussion groups and jointly discuss solutions to problems. Teachers only need to give some advice when the students are discussing in groups so that the students can solve the problem on their own. In this way, the student will have more optimistic and active attitude to learning. Only students who sincerely want to learn can learn better and give full play to development of their personalities.

\section{E. Encourage students to improve the innovation awareness}

The traditional physical education teaching contains mainly some running and jumping exercises, but such basic teaching contents are no longer suitable for the current physical education. It's feasible to adopt the basic contents of the teaching materials as the basis in the physical education teaching process to give full play to the advantages of good teaching environments, and to design innovative sports teaching contents so as to encourage students to think creatively and be proactive. At the same time, efforts are being made to create conditions for students of innovate learning so that students can sharpen their wits to discuss with teachers about better methods of physical education and learning.

\section{F. Cultivate the students' capacity of evaluation}

Learning to do a self-assessment and evaluate others and things is an expression of improvement in learning. Good expression is the basis for evaluation. In the physical education teaching, students are allowed to participate in the evaluation, so that students can actively participate in physical education activities and can improve their ability to express themselves and communicate with each other. In the process of evaluating other people, through comparing themselves with others, the students can discover the existing problems and deficiencies, and then according to self-exploration, gradually build better personalities. At the same time, in order to provide such opportunities for students, what is should be done is to create a free and harmonious evaluation system and environment.

\section{ConClusion}

In physical education teaching, the methods and ways of physical education teaching should be adopted to give full play to the educational functions of physical education. And it is necessary to understand each student's personality 
characteristics, then seriously study the influence from physical education teaching on student's personalities in various aspects, and according to the differences of student's personalities to formulate the optimal sports teaching plans and teach students in accordance with their aptitude so that each student can have the chance to show herself or himself, and fully develop its own personalities. In specific physical education teaching, the school should consider the practical needs of students to establish various types of courses that are helpful to students and attract students' interests. Physical education can be employed to guide students to cultivate good interests and hobbies, and make contributions to cultivation of students' personalities after the implementation for a long term. Finally, the overall development of physical and mental health will be truly achieved.

\section{ACKNOWLEDGMENT}

This work has been supported by the Colleges and Universities Outstanding Youth and Middle Aged Scientific and Technological Innovation Team Project of Hubei Province (No.T201628).

\section{REFERENCES}

[1] Han Lingling. A Research on Physical Education and Development of Students' Personalities[J]. Contemporary Sports Technology, 2011,1(05):53-55. (in Chinese)

[2] Yang Yuanhui. A Brief Research on College Physical Education and Development of College Students' Personalities[J]. Labor Security World, 2015(24):15+20.(in Chinese)

[3] Da Qin. How to Promote the Development of Students' Personalities in Physical Education[J]. Middle School Curriculum Tutoring (Teacher Education), 2017(07):34.(in Chinese)

[4] Wang Xing. A Study on Teaching Management of Cultivating Creative Talents in Sports Colleges[D]. Shanghai University of Sport, 2009.(in Chinese)

[5] Gao Hong xia. A Study on School Physical Education and Development of Students' Personalities[J]. Arts and Science Navigation(Middle), 2011(04):66.(in Chinese)

[6] Zhang Youwei. A research on Development of Personalities and Cultivation of Teamwork Spirit for Students Majoring in PE Teaching in Higher Physical Education Institutes of Beijing[D]. Capital University of Physical Education and Sports, 2013(in Chinese)

[7] Robazza Claudio, Bortoli Laura, Bertollo Maurizio, Carraro Attilio. Approach-avoidance individual differences in changing students' responses to physical education.[J]. Perceptual and Motor Skills, 2007,104(3 Pt 1). 